\title{
PERAN DINAS SOSIAL DALAM PENANGANAN ODGJ ( ORANG DENGAN GANGGUAN JIWA ) KECAMATAN POLEWALI KABUPATEN POLEWALI MANDAR
}

\author{
${ }^{1}$ Andi Tenriangka , ${ }^{2}$ Nurfitrah, ${ }^{3}$ Abdul Khalik, \\ ${ }^{1}$ Ilmu Pemerintahan, ${ }^{2}$ Fakultas Ilmu-ilmu Sosial dan Ilmu Pemerintahan, ${ }^{3}$ Universitas Al \\ Asyariah Mandar.
}

Anditenriangka742@gmail.com

\begin{abstract}
ANDI TENRIANGKA, 2021 "The Role of the Social Service in Handling People With Mental Disorders (ODGJ) Polewali District, Polewali Mandar Regency". Supervised by Mrs. Nur Fitrah as Advisor I and Mr. Abdul Khalik as supervisor II.

This study aims to determine 1 . How is the role of social services in handling ODGJ in Polewali District, Polewali Mandar Regency, 2. Inhibiting factors and supporting factors in handling ODGJ in Polewali District, Polewali Mandar Regency. This type of research does not use calculation procedures or numbers and does not use measuring instruments with this qualitative method only describing an event or occurrence.

The results showed that the role of the Social Service in handling ODGJ sufferers was still limited. In addition, the Social Service had carried out its role in handling ODGJ people in Polewali District, namely by facilitating ODGJ sufferers such as providing assistance in the form of basic necessities and medicines. So that the roles played by the Social Service Office in handling people with ODGJ in terms of the number of recipients of social assistance can be said to have increased although not by a significant amount. The inhibiting factor in handling ODGJ is the absence of a place or place for rehabilitation in Polewali Mandar Regency to accommodate ODGJ in order to develop their personality to be better and the absence of a regional regulation that regulates ODGJ.
\end{abstract}

Keywords: Rehabilitation, ODGJ

\section{ABSTRAK}

ANDI TENRIANGKA, 2021 " Peran Dinas Sosial Dalam Penanganan Orang Dengan Gangguan Jiwa (ODGJ) Kecamatan Pol ewali Kabupaten Polewali Mandar". Di bi mbing oleh Ibu Nur Fitrah sel aku Pembi mbing I dan Bapak Abdul Khaliksel aku pembimbing II.

Penelitian ini bertujuan untuk mengetah ui 1.Bagaimana peran dinas sosial dalam penanganan ODGJ di Kecamatan Polewali Kabupaten Polewali Mandar, 2. Faktor pengh ambat dalam penanganan ODGJ di Kecamatan pol ewali Kabupaten Pol ewali Mandar.

Jenis penelitian ini bersifat kualitatif yang jenis pen elitiannya tidak menggunakan prosedur perh i tungan atau angka-angka dan tidak menggunakan alat ukur, Metode kualitatif ini h anya mem aparkan suatu peristiwa atau kejadian. Sumber data yang digunakan adalah sumber primer yaitu informasi yang bersumber dari pengamatan langsung lokasi penelitian dengan cara observasi dan wawancara.

Hasil penelitian menunjukkan bah wa Peran Dinas Sosial dal am penanganan penderita ODGJ bel um maksi mal, Selain itu Dinas Sosial telah menjalankan perannya dalam penanganan Penyandang ODG J di Kecamatan Polewali yaitu dengan memfasilitasi para Penyandang ODGJ seperti memberikan bantuan berupa sembako dan obat-obatan. Sehingga peran-peran yang dilakukan Dinas Sosial dal am penanganan Penyandang ODGJ dari segi juml ah penerima bantuan sosial dapat dikatakan meningkat wal aupun tidak dengan juml ah yang si gnifi kan. Faktor pengh ambat dal am penanganan ODGJ yaitu bel um adanya wadah atau tempat reh abilitasi di Kabupaten Polewali Mandar untuk menampung ODGJ guna membi na pribadi mereka agar menjadi lebi h baik dan belum adanya Perda yang mengatur ODGJ.

Kata Kunci : Rehabilitas, ODGJ 


\section{PENDAHULUAN}

Masalah kesehatan jiwa di dunia sudah menjadi masalah kesehatan global yang sangat serius. Hampir 400 juta penduduk dunia menderita masalah kesehatan jiwa dan gangguan perilaku, satu dari empat keluarga sedikitnya mempunyai seorang anggota keluarga dengan gangguan kesehatan jiwa (WHO, 2011) Setiap empat orang membutuhkan pelayanan kesehatan, seorang diantaranya mengalami gangguan jiwa dan seringkali tidak terdiagn osis secara tepat sehingga tidak memperoleh perawatan dan pengobatan dengan tepat. Menurut World federation of mental health atau disingkat WFMH (2016) dalam (ikatan dokter Indonesia, 2016) ada fakta mencengangkan, bahwa satu dari empat orang dewasa akan mengalami masalah kesehatan jiwa pada satu waktu dalam hidupnya bahkan, Setiap 40 detik di suatu tempat di dunia ada seseorang yang meninggal karena bunuh diri. (WHO,2011)

Gangguan jiwa adalah penyakit yang menyerang sel saraf, yang mempengaruhi emosional dan psikologis seseorang di Indonesia.Gangguan jiwa identik dengan sebutan "orang gila" dan sering mendapatkan perlakuan yang tidak menyenangkan dari Masyarakat atau orang yang disekitarnya dan membuat emosionalnya terganggu sehingga keluarganya memilih untuk memasung. Memasung bukanlah solusi yang baik untuk gangguan jiwa karena akan membuat psikologisnya semakin buruk dan sehingga tidak menyembuhkan tetapi membuat si penderita semakin merasa tertekan.

Buruknya pelayanan publik di Indonesia sering menjadi variabel penting yang mendorong munculhya krisis kepercayaan masyarakat kepada pemerintah. Serta baik buruknya pelayanan tergantung dari bagaimana pelayanan itu diberikan dan siapa yang memberikan pelayanan. Pada dasamya setiap manusia membutuhkan pelayanan, bahkan secara ekstrinm dapat dikatakan bahwa pelayanan tidak bisa dipisahkan dari kehidupan manusia.Namun nyatanya pelayanan publIk di Indonesia masih belum sesuai dengan harapan. Hal utama yang seharusnya menjadi perhatian oleh pemerintan adalan bahwa harapan masyarakat akan pelayanan kesehatan yang berkualitas sangat tingg, namun pada kenyataannya di lapangan bahwa pelayanan kesehatan yang diberikan tidak sesuai dengan apa yang diharapkan. Sehingga tenadi kesenjangan antara ekspektasi masyarakat dengan pelayanan nyata yang diberikan oleh pemerintah. Menurut Bl, W., Syaeba, M., \& Rustan, I. R. 2020 yang seharusnya dilakukan untuk membentuk pelayanan yang berkualitas dengan metode pengumpulan data yang digunakan adalah metode observasi, wawancara yang harus digunakan lebih awal.

Di Indonesia hanya 1 provinsi yang mempunyai peraturan mengenai gangguan jiwa yaitu Provinsi Jawa Barat, Daerah Istimewa Yogyakarta (DIY).Yang membuat peraturan Gubernur, yang secara spesifik menangani gangguan jiwa.Daerah istimewa Yogyakarta hanya memiliki satu peraturan yang membahas masalah spesifik pemasungan penderita gangguan jiwa yaitu 
peraturan Gubernur Daerah Istimewah Yogyakarta No 81 tahun 2014, untuk pedoman penanggulangan pemasungan.Sampai saat ini belum ada provinsi atau kabupaten yang membuat peraturan daerah secara spesifik mengatur mengenai gangguan jiwa atau tunalaras termasuk, Provinsi Sulawesi Barat.

Di Kabupaten Polewali Mandar menjadi salah satu Kabupaten yang belum ada sama sekali yang mengatur mengenai hal tersebut. Termasuk kurangnya fasilitas kesehatan yang layak untuk menangani penderita gangguan jiwa padahal sudah jelas tertulis melalui Undang-undang Nomor 18 tahun 2014 tentang kesehatan jiwa dalam pasal 81 yang menyatakan, bahwa pemerintah pusat dan pemerintah daerah wajib melakukan rehabilitasi terhadap ODG "orang dalam gangguan" dan pasal 42 Undang-undang HAM "setiap warga Negara berhak yang berusia lanjut cacat fisik dan atau cacat mental berhak memperoleh perawatan, pendidikan, pelatihan dan bantuan khusus atau biaya Negara, untuk menjamin kehidupan yang layak sesuai dengan martabat kemanusiannya, Meningkatkan rasa percaya diri dan kemampuan berpartisipasi dalam kehidupan bermasyarakat berbangsa dan bernegara"

Oleh karena itu Pemerintah Daerah Kabupaten Polewali Mandar sebaiknya, membuat regulasi peraturan Daerah mengenai gangguan jiwa dan memberikan anggaran kepada Dinas Sosial sesuai dengan Undang-undang yang berlaku di Indonesia mengenai penanganan gangguan jiwa dan perlindungan, agar perlindungan mereka terjamin secara sah, dilihat dari beberapa kasus yang terjadi khususnya di Kecamatan Polewali Mandar masih banyaknya gangguan jiwa yang terlantar dan tidak mendapat penanganan secara khusus termasuk tempat rehabilitasi,

Yang kita ketahui bersama bahwa di Kabupaten Polewali Mandar terkhusus Kecamatan Polewali, dikarenakan banyaknya gangguan jiwa yang sering berkeliaran di jalanan membuat Masyarakat resah, bahkan sampai ada yang terpaksa dipasung oleh keluarganya karena mereka tidak mempunyai pilihan lain, yang seharusnya penderita gangguan jiwa mempunyai tempat rehabilitasi untuk proses penyembuhan secara total, tetapi tidak terdapat sama sekali tempat khusus yang menangani hal tersebut, sesuai dengan Pasal 149 UU kesehatan:

"Penderita gangguan jiwa yang terlantar, menggelandang, mengancam keselamatan dirinya atau orang lain, mengganggu ketertiban dan atau keamanan umum wajib mendapatkan pengobatan dan perawatan di fasilitas pelayanan kesehatan."

Masih banyaknya kalangan yang menganggap gangguan jiwa tidak harus menjadi salah satu fokus perlindungan dan memandang sebelah mata adalah hal yang sangat disayangkan sekali, karena mereka juga mempunyai hak yang sama. Meski demikian telah kita ketahui bersama bahwa di Kecamatan Polewali Mandar masih terdapat banyak gangguan jiwa yang sering berada di 
jalan, sehingga sangat membahayakan baik dirinya sendiri maupun orang lain. akan tetapi fasilitas di Polewali Mandar ter-khusus Kecamatan Polewali belum memadai untuk menangani secara serius, seperti Rumah sakit khusus penderita gangguan jiwa dan belum ada sama sekali, yang seharusnya gangguan jiwa mempunyai tempat khusus untuk proses penyembuhan secara total dan pencegahan untuk mengurangi peningkatan gangguan jiwa yang ada di Kecamatan Polewali.

Berdasarkan beberapa permasalahan diatas, maka penulis tertarik untuk melakukan penelitian dengan judul "Peran Dinas Sosial Dalam Penanganan ODGJ (orang dengan gangguan jiwa) Kecamatan Polewali Kabupaten Polewali Mandar"

\section{METODE PENELITIAN}

Metode yang digunakan penulis dalam penelitian ini yaitu metode kualitatif yang jenis penelitiannya tidak menggunakan prosedur perhitungan atau angka angka dan tidak menggunakan alat ukur, Metode kualitatif ini hanya memaparkan suatu peristiwa atau kejadian. Menurut Sugiyono(2016:9) metode penelitian kualitatif adalah metode penelitian yang digunakan untuk meneliti pada kondisi obyek yang alamiah dimana peneliti adalah sebagai instrumen kunci. Secara umum metode penelitian terdiri atas dua kata metode dan penelitian. Jenis penelitian yang digunakan dalam penelitian ini adalah dengan menggunakan metode penelitian jenis kualitatif. Dimana pada jenis penelitian ini berdasarkan metode fenomena sosial yang menyelidiki masalah manusia. Bahkan dalam penelitian ini peneliti membuat gambaran yang kompleks, memeriksa kata-kata, laporan rinci dalam pandangan responden dan melakukan penelitian alami.Bogdan dan Taylor dalam (Moleong, 2014:4) metode kualitatif adalah prosedur penelitian yang menghasilkan data deskriptif berupa kata-kata tertulis atau lisan dari orang-orang dan perilaku yang dapat diamati. Sugiyono (2011:11) menjelaskan bahwa penelitian deskriptif adalah penelitian yang dilakukan untuk mengetahui nilai variabel mandiri, baik satu variabel atau lebih tanpa membuat perbandingan, atau menghubungkan antara variabel satu dengan variabel lainnya.

Metode kualitatif mencari makna pengalaman partisipan, maka arah penelitian harus disesuaikan dengan masukan dari informan. Jadi titik berangkatnya adalah informasi partisipan. Praduga dan konsep peneliti harus disingkirkan. Hal ini mengungkap aspek lain dari metode kualitatif adalah aspek demokratis. Maksudnya bahwa masukan dan informasi partisipan mnenjadi sumber data yang sangat penting. Ide, pendapat dan pikiran mereka diakomodasi (Raco, 2018).

\section{HASIL DAN PEMBAHASAN}




\section{Hasil Penelitian}

Hasil Penelitian ini akan menguraikan seluruh hasil pengumpulan data penelitian tentang Peran Dinas Sosial Dalam Penanganan ODGJ (orang dengan gangguan jiwa) Kecamatan Polewali Kabupaten Polewali Mandar

1. Peran Dinas Soial Dalam penanganan ODGJ di Kecamatan Polewali Kabuaten Polewali Mandar.

Peran Dinas Sosial dalam penanganan penderita ODGJ masih terbatas. Keterbatasan sebagaimana terkait pada penanganan penderita ODGJ yang tidak merata, sehingga masih terdapat penyandang yang belum tersenutuh penyuluhan/sosialisasi mengenai adanya pelatihan keterampilan, adanya bantuan sosial yang bertujuan untuk meningkatkan kemandirian penderita ODGJ di kabupaten Polewali Mandar. Dinas Sosial selaku dinas yang menaunginya harus mampu berperan secara maksimal untuk memberdayakan para penderita ODGJ terutama yang telah memasuki tahap produktif dalam hidupnya. Sehingga selain dapat mengurangi beban keluarga, dan juga dapat mengurangi tingkat pengangguran di kecamatan polewali terutama, serta dapat meningkatkan taraf kemandirian penderita ODGJ itu sendiri.

2. Bentuk penanganan Dinas Sosial

Penanganan Dinas Sosial dalam penanganan Odgj masih terbatas. Keterbatasan sebagaimana terkait pada penanganan Odgj yang tidak merata, sehingga masih terdapat penyandang yang belum tersentuh penyuluhan/sosialisasi mengenai adanya adanya bantuan sosial yang bertujuan untuk meningkatkan kemandirian ODGJ di Kecamatan Polewali. Dinas Sosial selaku dinas yang menaunginya harus mampu berperan secara maksimal untuk memberdayakan para Odgj terutama yang telah memasuki tahap produktif dalam hidupnya. Sehingga selain dapat mengurangi beban keluarga, serta dapat meningkatkan taraf kemandirian Odgj itu sendiri.

3. Gambaran Sikap dan Dukungan keluarga terhadap ODGJ

a. Sikap Keluarga terhadap penyandang ODGJ

Sebagian besar keluarga berpendapat bahwa gangguan jiwa merupakan suatu kondisi yang berbeda dari orang normal pada umumnya, gangguan jiwa memiliki prilaku dan pemikiran yang tidak wajar sehingga berbeda dengan kondisi normal.

Berdasarkan wawancara yang dilakukan peneliti dengan Ibu Dalamah selaku ibu dari anak Penderita ODGJ yang berkediaman di Manding, beliau mengatakan bahwa :

"...... anak saya sudah 30 tah un mengidap penyakit ODGJ ini, penyakitnya ini merupakan penyakit keturunan dari bapaknya, tanggapan dari keluarga saya hanya memberi pendapat dan dukungan." (wawancara, 15 April 2021)

b. Sikap Keluarga secara kecenderungan untuk bertindak 
Sikap keluarga dalam menghadapi persoalan pada penderita gangguan jiwa sebagian besar menerima keadaan yang ada dan berharap semua dapat sembuh dan keluarga berusaha untuk tetap melakukan pengobatan.

Berdasarkan wawancara peneliti terhadap Ibu Dalamah tentang alasan mempasung anaknya si Lukman, mengatakan bahwa :

"Sebelum dipasung anak saya tidak pernah menggangu tetangga maupun dilingkungan sekitar, alasan saya mempasungnya karena sering pergi jauh tanpa arah" (wawancara, 15 April 2021)

Ibu Dalamah pun menceritakan tentang anaknya waktu berumur 30 tahun tentang pendapat keluarganya :

"Pada waktu itu keluarga sepakat untuk membawa anak saya kerumah sakit Jiwa yang berada di Makassar, akan tetapi tidak ada perubahan justru anak saya hampir saja mati karena tidak mau makan, sehingga saya memutuskan anak saya dibawa pulang saja ke Polewali Mandar, setelah sampai dirumah datanglahPak RT lingkungan setempat beliau menyarankan untuk dibuatkan ruang khusus agar supaya bebas bergerak tanpa harus dipasung, tapi apalah daya saya salah satu orang yang tidak mampu, saya hanya berharap anak saya mendapat bantuan dari pihak pemerintah daerah. Suatu waktu Ibu Kapolres datang berkunjung beserta Kepala Rumah Sakit Umum Daerah Polewali mandar, alhamdulillah beliau memberikan Sedikit bantuan berupa uang dan Obat-obatan untuk anak saya, setelah selang beberapa hari datang pula Tim dari Dinas Sosial dengan memberikan bantuan berupa Sembako dan Obat-obatan, besar harapan saya agar supaya Tim dari Dinas Sosial memberikan tempat rehabilitas untuk anak saya dan para penderita Penyandang ODGJ yang lain." (wawancara, 15 April 2021)

4. Faktor penghambat Dinas Sosial dalam penanganan penderita ODGJ

Yang termasuk faktor penghambat yaitu: Terdapatnya komitmen atau loyalitas ganda, Kerumitan yang melekat pada program itu sendiri, dan Jenjang pengambilan keputusan yang terlalu banyak

Berdasarkan hasil wawancara dia atas, peneliti menyimpulkan bahwa dalam penanganan yang dilakukan oleh Dinas Sosial Kabupaten Polewali Mandar dengan melakukan perhatian khusus bagi penderita ODGJ sebagai bentuk pembinaan awal dari pihak Dinas Sosial yang bekerja sama dengan Dinkes dan Rumah sakit daerah kabupaten Polewali Mandar.

\section{Pembahasan}

Berdasarkan hasil penelitian, Kendala yang dihadapi dalam penanganan ODGJ ini karena tempat penampungan/panti rehabilitasi belum ada. hal inilah yang menjadi hambatan mengapa sampai saat ini penanganan yang dilakukan belum sepenuhnya efektif, selain hambatan dalam penanganan ODGJ karena belum adanya wadah, dinas sosial, juga memiliki hambatan dalam melakukan bantuan sosial dikarenakan kurangnya dana. 
Peran Dinas Sosial dalam penanganan ODGJ ini sangat penting untuk menuntaskan penyandang masalah kesejahteraan sosial di Kecamatan Polewali, Dinas Sosial kabupaten Polewali mandar dalam hal menangani ODGJ di Kecamatan Polewali belum cukup efektif karena ODGJ hanya didata saja tidak cukup untuk mengurangi jumlah ODGJ di setiap Kecamatan yang ada di Kabupaten Polewali.

Ada beberapa kendala atau hambatan yaitu belum tersedianya panti rehabilitasi untuk membina atau menangani ODGJ dari berbagi hambatan yang ada di Dinas Sosial, salah satu cara untu mengatasinya yaitu dengan cara adanya kerja sama dari masing-masing pihak.

Dari beberapa pendapat di atas penulis menyimpulkan bahwa usaha-usaha untuk menangani ODGJ yang telah dilakukan oleh Dinas Sosial sudah berjalan cukup baik, namun dalam penanganan ODGJ Dinas Sosial memiliki hambatanhambatan yang akan mempersulit peran. Adapun hambatan-hambatan itu antara lain adalah sebagai berikut :

1. Hambatan dalam penanganan ODGJ ini yaitu belum tersedianya panti rehabilitasi sosial atau penampungan untuk ODGJ setelah tertangkap oleh tim Dinsos .

2. Kurangnya anggaran dana dalam program pemberdayaan dan pembinaan penanganan ODGJ. Selama ini berjalannya program pemberdayaan dan pembinaan ODGJ, berasal dari Dinas Sosial Kabupaten Polewali Mandar yang mana seluruh pendanaannya berasal dari pusat. Karena terbatasnya anggaran yang diperoleh dari alokasi anggaran sangat minim, maka penertiban, pemberdayaan, penanganan ODGJ sangat terkendala. Hal ini dapat dimaklumi setiap tahun Penyandang Masalah Kesejahteraan Sosial (PMKS), semakin meningkat, sedangkan anggaran Pusat harus dapat dibagi ke seluruh wilayah negara Republik Indonesia

\section{SIMPULAN}

Berdasarkan hasil penelitian dan pembahasan pada bab sebelumnya maka penulis menarik kesimpulan bahwa Dinas Sosial dalam penanganan Penyandang ODGJ telah melaksanakan perannya namun belum maksimal karena melihat dari segi jumlah penerima bantuan dari perannya yaitu peran fasilitatif yang dilaksanakan Dinas Sosial belum secara merata, dibuktikan dengan bantuan sosial yang diberikan masih terbilang minim bahkan tidak mencapai 20 persen dari jumlah keseluruhan penderita Penyandang ODGJ yakni sebanyak 8 orang se Kecamatan Polewali dikarenakan tidak adanya dana anggaran dari pemerintah daerah. Dinas Sosial Kabupaten Polewali Mandar dalam penanganan ODGJ di Kecamatan Polewali belum sepenuhnya berjalan dengan dengan efektif dikarenakan salah satu faktor yang menjadi penghambat dalam penanganan ODGJ yaitu belum adanya wadah atau panti rehabilitasi di 
Kabupaten Polewali Mandar untuk menampung ODGJ guna membina pribadi mereka agar menjadi lebih baik dan belum adanya Perda yang mengatur ODGJ.

\section{DAFTAR PUSTAKA}

Dermawan deden dan Rusdi. 2013. Keperawatan jiwa; konsep dan kerangka kerja Asuhan keperawatan jiwa. Yogyakarta: Gosyen Publising.

Goal N.J (2012). Kesehatan jiwa: Pusat penyembuhan penyakit jiwa dan gangguan kejiwaan

Lexy J. Moleong. (2014). Metode Penelitian Kualitatif. Bandung: PT Remaja

Rosdakarya

Sugiyono. (2011) Metode Penelitian Administrasi. Bandung, Alfabeta

Moleong, Lexy J. 2000. Metodologi Penelitian Kualitatif. Bandung: Remaja Rosda Karya.

pasal 148 ayat (1) dan pasal 149 Undang undang nomor 36 tahun 2009 tentang kesesatan (Undang-undang kesesatan)

Tyas. T. H. W. M. Minza,\& G. Lutfiyanto (ED) 2012. Psikologi untuk kesejahteraan masyarakat: pasung sebagai isu kesehatan jiwa di Indonesia

Jaya, Zulfikar, H. Sjuaib Hannan, and Abdul Khalik. "Analsis Pengembangan

Kapasitas Struktur Organisasi Terhadap Pelayanan Kesehatan Di Puskesmas Malunda." Journal Peqguruang: Conference Series. Vol. 2. No. 1. 2020 .

Bl, W., Syaeba, M., \& Rustan, I. R. (2020, November). Peranan Badan Perencanaan Pembangunan, Penelitian Dan Pengembangan Daerah Dalam Penyusunan Rencana Pembangunan Jangka Menengah Daerah Di Kabupaten Mamasa. In Journal Peqguruang: Conference Series (Vol. 2, No. 2) 